\title{
Plasma Application in Textiles
}

Hend Mohamed Ahmed ${ }^{1, *}$, A.A. El-Halwagy ${ }^{1}$, Amal abdel-Aaty $^{1}$, A. A. Garamoon ${ }^{2}$ ${ }^{1}$ Dyeing, Printing and Auxiliaries Department, Textile Research Division, National Research Centre, Cairo $12622{ }^{2}$ Center of plasma technology, Faculty of science, AlAzhar University, Nasr city, Cairo, Egypt.

\footnotetext{
CHEMICAL modification of cellulosic fabrics was early used as a tool for imparting to it new properties and increasing its effective application for different end-uses. Nowadays, physical technologies can advantageously replace some of these chemical modifications as environmental friendly processes. Plasma treatment is considered one of these physical technologies applied to nearly all the synthetic and cellulosic textile fabric. It modifies the fiber surface and leaves the bulk characteristics unaffected. It is fast growing field and finds some potential applications as an environmentally friendly process. Plasma treatment does not involve handling of hazardous chemicals and thus there are no problems of effluents compared with the chemical treatment.
}

\section{Cotton Fibers}

Fibers have been defined by the textile institute as units of matter characterized by flexibility, fineness, and a high ratio of length to thickness [1]. Fibers are the basic units from which all textile materials are made [2]. Textile goods are manufactured from fibrous material which may be either of natural or man-made origin [3]. Natural fibers are divided in three groups: vegetable fibers (cotton, flax, hemp, kenaf, sisal and other); animal or proteinic fibers (wool, silk); and non-organic or mineral fibers (asbestos) [4]. Figure 1 illustrates the classification for natural fibers [5].

Man made fibers are those, which are produced in industrial conditions and mainly, consist of organic heterochain and carbochain compounds; only a small part, of natural nonorganic compounds [4]. Figure 2 illustrates the classification for Man-made fibers [5].

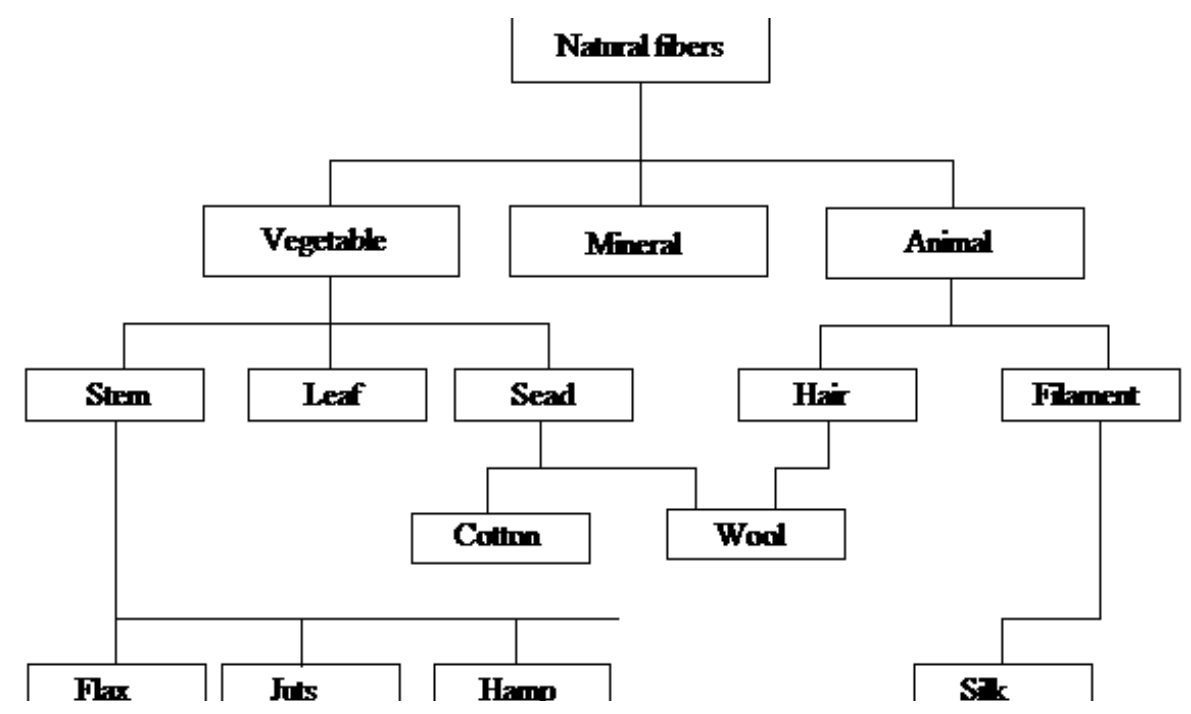

Fig. 1. Natural fibers-partial classification. 


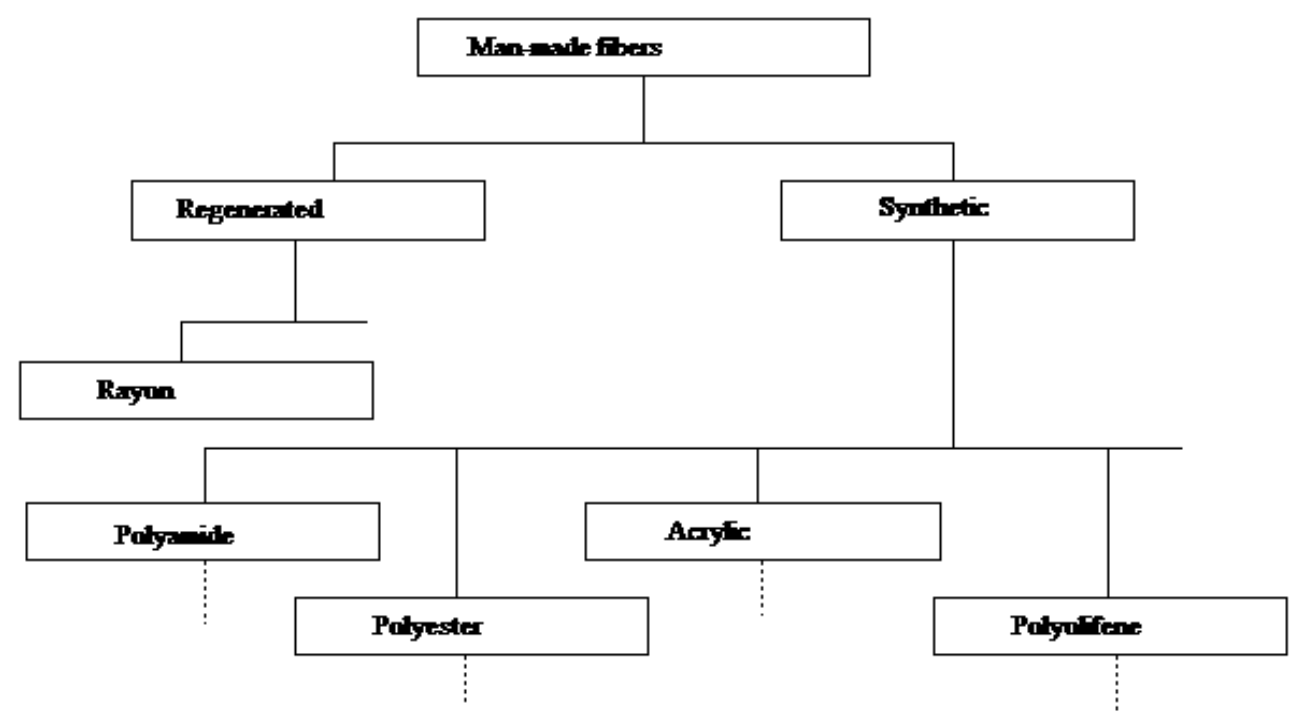

Fig. 2. Man-made fibers - partial classification.

Cotton as well as polyester fibers are the most widely used fibers in textile manufacture. In the following, a brief account about their structures and properties is reported [3]. Cotton is the oldest and most important of textile fibers. It has been used for thousands of years [6]. Cotton fiber has the shape of a tube with one breaking when the fiber is torn away from the seeds. The fiber properties are determined by its chemical composition and structure [4].

\section{Cotton fiber content in $\%$}

Cellulose

Pectin substances and pentodes

Nitrogen and protein substances

Fats and wax

Ash

The chemical elements are irregularly distributed in the fiber.

\section{Chemical Structure}

The molecules of cellulose, which is the main substance of the cotton fiber, together with admixtures join into macromolecules fibrils of elongated shape [4]. Like all cellulose fibers, cotton contains carbon, hydrogen, and oxygen with reactive hydroxyl $(\mathrm{OH})$ groups. The basic unit of the cellulose molecule is glucose which is the same for both natural and regenerated fibers. Cotton may have as many as 10,000 glucose units per molecule. The molecular chains are arranged in spiral form [7].

\section{J. Text. Color. Polym. Sci. 16, No. 1 (2019)}<smiles>CC1OC(C(C)OC2OC(C)C(C)C(O)C2O)C(C)OC1CO</smiles>

The chemical reactivity of cellulose is related to the hydroxyl groups (OH groups) of the glucose unit. These groups react readily with moisture, dyes, and many finishes. Chemicals such as chlorine bleaches break the molecular chain of the cellulose by attacking the oxygen atom between the two ring units or within the ring, rupturing the chain or ring. The cellulose molecule is a long, linear chain of glucose units. The length of the chain is a factor in fiber strength [7].

Recent literature showed that cellulose can be modified chemically by [3]:

i) Substitution of the hydroxyl groups, where by the molecules are changed through the introduction of side groups via etherification [8] or esterification [9] reactions. The chemical modification of cellulose is dependent on the type and extent of reaction performed as well as the nature of the subsistent groups. This type of reactions can eliminate or reduce 
some of the drawbacks of cellulose such as inflammability, susceptibility to rot and mildew, swellability, etc.

ii) Ability of reaction of cellulose with difunctional compounds which results in introduction of cross-links, stabilizing its structure. This mainly imparts crease and shrink resistances.

iii) Modification of the cellulose by creation of branches of synthetic polymers through grafting reactions [10-11].

\section{Fiber Properties}

- Microscopic

The longitudinal view of the fiber shows a ribbon like shape with twist, called convolutions, at irregular intervals. The diameter of the fiber narrows at the tip. The lumen may appear as a shaded area or as striation; this is more obvious in immature fibers. The cross section of the fiber usually shows three areas: the outer skin, or cuticle; the secondary wall; and the lumen. The contour varies considerably; some fibers are nearly circular, some are elliptical, and some are kidney shaped. Immature fibers are more irregular in contour than mature fibers [12].

- Physical

Color

Cotton is available in a range of colors. Naturally creamy white is highly desirable because it can be dyed or printed to meet fashion and consumer needs. These fibers may yellow or become more beige as they age. If it rains just before harvest, these fibers become grayer [7].

\section{Appearance}

Overall appearance retention is moderate. Cotton has very low resiliency. The hydrogen bonds holding the molecular chains together are weak, and when fabrics are bent or crushed, particularly in the presence of moisture, the chains move freely to new positions. When pressure is removed, there are no forces within the fibers to pull the chains back to their original positions, so the fabrics stay wrinkled [7].

\section{Tensile strength}

Strength of a fiber is indicated by the ability to resist being pulled or torn apart when subjected to stress or tension. Cotton fiber is relatively strong due to the intrinsic structure of layers of crisscrossed, minute, spiraled fibrils that compose the fiber cell [13].

\section{Heat Conductivity}

Heat conductivity of cotton fiber is low and the looser the cotton fiber mass, the lower the conductivity. This property is used for manufacturing cotton wadding. Cotton fiber in dry condition presents low electrical conduction owing to which cotton fabrics may be used as insulation. This electrical conduction increases with humidity [4].

\section{Absorbency}

The ease and extent to which moisture can penetrate into a fiber determines its absorbency. Once the outer protective cuticle of the cotton fiber is broken down by finishing processes, such as kiering and mercerizing, the fiber becomes very absorbent [14].

\section{- Chemical}

The action of acids on cotton

Boiling with dilute acids will ultimately hydrolyze the cellulose to glucose. Milder action by acids at lower temperatures gives rise to tendering with the formation of hydrocellulose. Nitric acids on account of its oxidizing action, differs from other acids in its behavior towards cellulose. Immersion for a short time in concentrated nitric acid causes some shrinkage accompanied by a degree of increase in tensile strength and affinity for dyestuffs. Prolonged action of cold nitric acid oxidizes the cellulose to oxy cellulose and finally breaks it down to oxalic acid, the reaction being accelerated at higher temperature [15].

The action of alkalis on cotton

Mild alkalis, such as sodium carbonate, have no action on cellulose at low or at higher temperatures in the absence of air. In the presence of oxygen, however, oxycellulose is produced gradually with consequent tendering. A solution of 20 percent sodium hydroxide is used to mercerize cotton, making it stronger, smoother, and had acquired a greater affinity for dyes [16].

\section{Effect of organic solvents}

Cotton fiber is insoluble in most organic solvent; it dissolves in few complex solutions, such as cuprammoniom. Dry cleaning solvents do not have any deleterious effect [17].

\section{Effect of light}

Cotton fiber oxidizes, turning yellow and losing strength from exposure to sunlight over a prolonged period of time. Cotton fabric should therefore be shaded from direct sun light [18].

Resistance to perspiration

Perspiration may be alkaline or acidic, depending upon the individual's metabolism. J. Text. Color. Polym. Sci. 16, No. 1 (2019) 
Since cotton resistant to alkali, alkali perspiration does not deteriorate cotton. However, acid perspiration has a slightly deteriorating effect [19].

Affinity for dyes

Cotton has a good affinity for dyes. It is dyed best with vat dyes, but azoic and reactive dyes may also be effectively used. Color fastness is generally good, but specific condition should be considered [20].

\section{- Mechanical}

The total elongation of cotton fibers at rupture (depending on the quality) amounts to 4-8\%, half of which is due to flexible and elastic elongation. The resilient breaking elongation of the cotton is higher than that of bast fibers, yet inferior to that of wool and silk [4]. Elasticity refers to the extent to which a fiber can be elongated by stretching and then returning to its former condition of size or length. Cotton fiber has very little natural elasticity [17].

\section{- Thermal}

Cotton burns readily and quickly with the smell of burning paper. It leaves a small amount of a fluffy, gray ash. Long exposure to dry heat about $300^{\circ} \mathrm{F}\left(150^{\circ} \mathrm{C}\right)$ will cause the fiber to decompose gradually, and temperatures greater than $475^{\circ} \mathrm{F}$ $\left(250^{\circ} \mathrm{C}\right)$ will result in rapid deterioration. Normal exposure to heat encountered in routine care and processing will not damage cotton, but fabrics will scorch if ironed with too high temperatures. Finishes, such as starch or durable press, increase the tendency to scorch [12].

\section{Polyester Fibers}

Polyester fibers is defined as a manufactured fiber in which the fiber-forming substance is any long-chain synthetic polymer composed of at least 85 percent by weight of an ester of a substituted aromatic carboxylic acid, including but not restricted to substituted terephthalate units $\mathrm{P}\left(-\mathrm{R}-\mathrm{O}-\mathrm{CO}-\mathrm{C}_{6} \mathrm{H}_{5}-\mathrm{C}-\mathrm{O}-\right)$ and parasubstituted hydroxyl-benzoate units $\mathrm{P}(-\mathrm{R}-\mathrm{O}-$ $\left.\mathrm{C}_{6} \mathrm{H}_{4}-\mathrm{CO}-\mathrm{O}-\right)$ " [12]. Polyester, polyethylene terephthalatearethemostimportantsynthetictextile fibers. These are manufactured under different names such as, Terylene(ICI), Terene(CAFI, India), Dacron(Du Pont), Lavsan(USSR). Tergal (Sociate Rhodiaceta, France), Terital (Societ Rhodiatoce, Italy), Tetoron (Teijin Ltd), Trevira (Hoechst) etc. certain modified polyester is also manufactured. These include kodel (derived from 1:4 dihydroxycyclohexane) of Eastman Kodak, U.S.A, and Vycorn (derived from isophthalic acid) of Goodvear Beaunit Mills, U.S.A [19].

\section{Chemical Structure}

Polyester fibers are synthetic textile fibers of high polymers (condensation products) which are obtained by esterification, especially of dicarboxylic acids, with glycols or glycol derivatives or by ester exchange reaction between dicarboxylic acid ester and glycols. Terylene is made by polymerizing, using ester exchange reaction between dimethyl terephthlate and ethylene glycol [19].

Dacron is made by polycondensation reaction using terephthalic acid and ethylene glycol. It is clearly seen from the above reactions that both Terylene and Dacron are essentially the same and that they differ in that whereas the former contains a methyl ester group at one of the macromolecule. The latter contains an acid group instead [19].

\section{Fiber Properties}

\section{- Microscopic}

A longitudinal view of polyester fiber exhibits uniform diameter, smooth surface, and a rod-like appearance. The cross section may be perfectly round or lobal in shape. The modifications in which trilobal- and pentalobal - shaped filaments are formed are the most popular [12].

- Physical

Color

Polyester can be made in any length or diameter required for potential end uses. The fiber is partially transparent and white or slightly off-white in color. Pigment can be combined with the spinning solution, which permits control of the degree of luster- not color. Optical brighteners are frequently added to produce clear, bright fibers [12].

\section{Appearance}

Resiliency refers to the extent and manner of recovery from deformation. Polyester has a high recovery when the elongation is low, an important factor in the apparel and furnishings markets [7]. Resiliency makes the polyester especially good for fiberfill in quilted fabrics such as quilts, bedspreads, parkas, and robes, and in padding for furniture, futons, and mattresses [7].

\section{Tensile strength}

The strength, or tenacity, of polyester varies with the type of fiber; however, as a general category, polyester would be considered a relatively strong fiber. Its strength is not affected by moisture. Regular filaments have a breaking tenacity of 4-7 g /d; high-tenacity filaments are rated at 6.3-9.5 g/d [12]. 
The strength of polyester varies widely; it depended on the end use and is controlled by the manufacturer. Polyester has a very high dry and wet tensile strength [20].

Heat conductivity

Fabrics of polyester fiber are good conductors of heat; it would be warmer than if made of cotton. One of the reasons for the apparent warmth of polyester is its low absorbency [21].

\section{Absorbency}

Although polyester is nonabsorbent, they do have wicking ability. This quality makes polyester relatively comfortable to wear in warm weather, as perspiration is carried to the surface of the fiber and evaporated. Multilobal fiber cross sections improve the wicking qualities of polyester. Special finishes can be applied to polyester to make it more hydrophilic [12].

\section{- Chemical}

The action of acids

Polyester fibers have excellent to good resistance to mineral and organic acids. Highly concentrated solution of mineral acids, such as sulfuric acid, at high temperatures will result in degradation [21].

\section{The action of alkalis}

At room temperature, polyester has good resistance to weak alkalis and fair resistance to strong alkalis. This resistance is reduced with increased temperature [22].

\section{Effect of organic solvents}

Polyester fiber shows high resistance to most of the common organic solvents, example acetone, dioxin, ether, methyl alcohol and carbon tetrachloride. The range of chemicals will dissolve polyester fiber at normal or moderate temperatures are limited, and the only chemicals - which as a class - will do this are phenols. Most phenols will swell or dissolve polyester fiber depending on the temperature and concentration used. Hot $\mathrm{m}$-cresol destroys the fiber and mixtures of phenol in trichloroethane dissolve the fibers [22].

\section{Effect of light}

Polyester has good resistance to degradation by sunlight; fabrics of polyester are therefore well suited for outdoor use. Over a prolonged period of exposure to direct sunlight however, there will be a gradual deterioration of the fibers [23].

\section{Resistance to perspiration}

Polyester has no significant loss in strength on continued contact with either acidic or alkaline perspiration [23].

\section{Affinity for dyes}

Polyester fiber is difficult to dye, since there are no chemical groups in the polyester molecule that will unite with dyestuffs and the molecules are packed so, there is no space to wedge in dye molecules. Also, the interchain forces are so strong that high temperatures are required to lose them so dye molecules can enter. In darker shades, expansive dye assistants or carriers are needed and these must be removed from the fiber after dyeing preserve light fastness. Only by use of disperse, azoic and pigment dyes at high temperature. Some polyester is modified to take basic dye. Also the enzyme treatment could result in enhancing hydrophilicity and increased cationic dye binding. For example, using polyester, enzymatic improvement of many undesirable properties of polyester under mild condition has been demonstrated [24-25].

\section{- Mechanical}

Polyester fibers shrink as much as $20 \%$ during wet finishing operations. Consequently, finished woven and knitted polyester fabrics will not shrink and have excellent dimensional stability [23].

\section{- Thermal}

Polyester fibers are the most thermally stable of all synthetic fibers. As with all thermoplastic fibers, its tenacity decreases and elongation increases with rise in temperature $150^{\circ} \mathrm{C}$, the fiber retains half of its original tenacity. The strength remains at this level for several days, but on cooling to $20^{\circ} \mathrm{C}$, it returns almost to its initial value [5].

\section{Textile Printing}

Color designs are produced on fabrics by printing with pigments or dyes in paste form or by positioning pigments or dyes on the fabric with specially designed machines. Printing is used to add color in localized areas only. Wet prints use a thick liquid paste; dry prints use a powder. Printed fabrics usually have clear-cut edges in the design portion on the face and the color seldom penetrates completely to the back of the fabric [7].

\section{Printing Paste}

It consists of dyes or pigments (colorants), solvents, thickeners and various auxiliary substances which are necessary for the color fixation. Irrespective of the nature of the dye, the printing paste must have a certain viscosity which is necessary for obtaining sharply defined outlines of the design of the fabric. The printing paste 
must not bleed on the fabric and must give a sharp design; a deep penetration of the dye inside the material is also desirable [26].

\section{Colorants}

The colorants used in textiles are based principally upon organic dyestuffs and pigments, with some inorganic pigments also in use [27-29]. Dyestuffs (reactive and disperse in our study) are used mainly in traditional dyeing and printing of textile materials while pigments are used in fabric pigment printing, mass-pigmentation of manufactured fibers and in some pigment dyeing processes [28]. Disperse dyes are designated as being anthraquione, azo, quinophthalone, azomethine, stilbene or nitrodiarylamine derivatives. These dyes are used for the normal dyeing and printing procedures to color polyester, polyamide and acetate textile fibers. These dyes are classified further as being low energy, medium energy and high energy types [30]. When printing fabrics made from polyester fibers, the fixation conditions are more rigorous than on other disperse dyeable fibers, owing to the slower diffusion of disperse dyes in the fiber. For continuous fixation the prints are exposed to super heated steam under pressure at $170-180{ }^{\circ} \mathrm{C}$ for $6-8$ minutes [31]. Reactive dyes, this class represents the main dye group for cellulosic fibers, i.e. cotton and rayon. Depending on the different levels of reactivity and affinity of the dyes to cellulose, and on the available equipment, a number of different fixation methods can be used. The selection of suitable thickeners is important because of the ability of the fiber-reactive dyes to react with the hydroxyl groups that are found in traditional thickeners such as starch. This reduces efficient use of dye, makes removal of the thickener after printing difficult, and gives the print a harsh handle. Sodium alginate is the preferred thickening agent. Fixation in steam of 100-105 ${ }^{\circ} \mathrm{C}$ takes 2-8 minutes; in super heated steam of $150-180^{\circ} \mathrm{C}, 1-5$ minutes; and in dry heat of 150 $200^{\circ} \mathrm{C}, 1-5$ minutes [32].

\section{Thickeners}

Thickeners form the basis of all print pastes and are the vehicle to which all the other printing auxiliaries and dyestuffs are added [33]. They can be described as colloids prepared usually from natural or synthetic materials. They are characterized by high viscosity and have a gel like structure. The choice of thickener depends upon type of dyestuff and cloth used, ability to withstand fixation without breaking down, and to

J. Text. Color. Polym. Sci. 16, No. 1 (2019) wash out easily from the finished print, leaving no residue [33]. Thickening agents can be classified into three main classes [34-35]:

I- Thickening agents based on natural products e.g polysaccharide

II- Thickening agents based on synthetic products

III-Thickening agents based on emulsions

In this thesis, special emphasis is made on the use of thickening agents based on polysaccharide and synthetic products such as sodium alginate and alcoprint respectively.

\section{- Polysaccharide thickening agents}

The structural elements, on which the polysaccharides are based, are very similar to each other, although the individual substances often show a different behavior. The chemical and physical properties of the thickening agents containing these substances are largely determined by the manner in which these structural elements are linked, as well as by the form and size of macromolecules. The super molecular structure is another important factor which determines the physical properties of the thickening agents [3435]. A brief idea will be given on one of the most important natural thickening agents which are sodium alginate.

\section{Sodium Alginate}

Sodium alginate is found in most brown seaweeds (the principle colloid is alginic acid) and is used as a thickener for printing as well as being widely used in the food industry. Extraction of the alginic acid from the brown seaweeds is done by digestion with solutions of sodium carbonate, while purification can be accomplished by precipitation as the calcium salt, reconversion to the free alginic acid and neutralization to give the desired salt [33]. Commercially produced high-viscosity alginates have relative molecular mass values of over 150 000, (D.P.of about 750) but lower relative molecular mass materials are also available. The monomer units are D-Mannuronic acid and L-Guluronic acid in $(1 \rightarrow 4)$ linked linear polymer with blocks of $\beta$-Mannuronide, $\alpha$-Guluronide and alternating copolymer segments. The copolymer segments are apparently the most readily hydrolysed. The typical ratio of mannuronic to guluronic units is 1:5:1[36-40]. Manufacturers and users of alginates have long been aware of differences in the behavior of alginates from different species of algae. It is now known that the proportion of 
mannurnic and guluronic acids vary from one species to another. Moreover alginates with a wide range of molecular weights are obtained. The most probable structure of the two forms of alginic acid is shown alongside the structure of cellulose. Print paste made with an alginate thickener give smooth, level shades over large areas and allow the dye to penetrate deep into the fibers. After printing, the dried paste remains relatively supple so avoiding cracking prior to fixation. This thickener also washes out easily, returning the cloth to its original state [33].

\section{-Synthetic thickener agents}

Synthetic thickening agents are long chain polymers derived from substituted vinyl compounds $\mathrm{H}_{2} \mathrm{C}=\mathrm{CHX}$, where $\mathrm{X}$ represents many different functional groups. These vinyl compounds are easily polymerized either by a free radical mechanism or by addition of ionic substance [41]. The resultant product is a synthetic polymer which when properly modified can be used as a print thickener. Polyvinyl alcohol is an important example of this group.

\section{Printing Styles}

There are three basic styles to print a color on fabric namely: direct, discharge, and resist [42].

\section{Direct Printing}

The most common style for applying a color pattern is direct printing. It may be done on white fabric or over a previously dyed fabric, in which case it is called over printing the dyes are usually dissolved in a limited amount of water to which a thickening agent has been added to give the necessary viscosity to the print paste. All pastes or printing materials contact the fabric surface with no subsequent processing alterations [43].

\section{Discharge Printing}

The discharge style depends on dyeing the fabric first and then printed with a chemicals that will destroy the color in designed areas [42]. Sometimes the base color is removed and another color printed in its place but usually a white area is desirable to brighten the over all design. Thus in discharge style of printing, a readily reducible dye, say azo dye, is dyed on a cloth and a reducing agent like sodium sulphoxylate formaldehyde, is printed and the fabric steamed, when the dye at the printed portion is destroyed by the reducing agents. The final washing removes the dye decomposition products there by producing a white printed effect on a colored ground. This is known as the white discharge style of printing. By incorporating a dye, which is not dischargeable by reducing agent, in the discharge printing paste and printing of the dyed cloth followed by steaming, a colored printed effect on a differently colored ground can be produced (colored discharge style) [44].

\section{Resist Printing}

The resist printing style, as its name implies, comes from printing the material with a substance which will resist dyeing later. The dye will affect only the parts that are not covered by resist paste and hence produce a pattern on a colored ground. Resist style are divided into chemical (those that employ agents such as glyoxal-bisulfite adducts or stannous chloride) and physical (those that use wax to block the fiber from being dyed) [45-59]. Each of these printing style used on one or more methods of application described below.

\section{Plasma Modification}

Plasma is an ionized gas. When a solid is heated sufficiently that the thermal motion of the atoms break the crystal lattice structure apart, usually a liquid is formed. When a liquid is heated enough that atoms vaporize off the surface faster than they re-condense, a gas is formed. When a gas is heated enough that the atoms collide with each other and knock their electrons off in the process, a plasma is formed: the so- called "fourth state of matter"[60]. It could also be defined as " Quasineutral gas of charged and neutral species that, exhibits collective behavior" quasi-neutrality implies that the number of the positive charges is almost equal to the number of the negative charges and the collective behavior arises from the fact that the motion of the charged species does not depend only on the local region but also on remote region because of the long range coulomb force between charged species [61]. Generally, plasma can be easily generated by gas breakdown through an application of an electric field such as Direct Current (DC), Alternating Current (AC), Higher Frequency (HF), Microwave and Optical Frequencies. A breakdown is usually initiated by a few free electrons that exist in the gas at room temperature due to cosmic ray (sometimes it is required to use UV radiation to liberate more free electrons from the electrode surface). These free electrons are accelerated by the applied electric field which imparts energy to them, and this energy is converted to thermal energy as a result of elastic collisions with gas atoms or molecules. When the electron energy exceeds the ionization energy of the gas, inelastic collisions take place 
resulting in the gas being excited and ionized which leads to more free electrons, and these electron multiplication processes continue until a steady state of ionization is reached. Therefore, electrons play an important role in plasma [60].

\section{Physical Processes in Plasma}

It was thought that gases are good insulators for electricity and so no current could pass when a potential difference is applied between two electrodes in any gas. But now, it is known that when a sufficient electric field is established in the gas and initial source of ionization in the gas is available, then the gas becomes conductor and the transition from an insulating to an almost perfect conducting state can take place. This transition is called electrical gas breakdown [60]. This transition depends on the ionization processes occurring in the gas which take place at or near electrodes surface. These processes can be divided into two main processes, ionization processes and de-ionization processes. Ionization processes are divided into two main processes [62-64]:

a) Primary ionization process which is electronatom collision. b) Secondary ionization processes. These processes can be subdivided into two types.

i) The secondary ionization processes that take place in the bulk of the gas e.g. positive ionatom collision, photo ionization, thermal ionization, excited atom-atom collision, chemical and nuclear reactions, etc.

ii) The secondary ionization processes that take place at the cathode e.g. thermo-ionic emission, photo emission, positive ions bombardment, excited atom impact, field emission, chemical and nuclear reactions, etc. De-ionization processes in the gas include thermal diffusion, recombination, am-bipolar diffusion, etc.

\section{Types of Plasma}

When reference is made today to plasma, it is first necessary to state more precisely the type of plasma technology concerned; and in the terminology of this technique, plasma can be divided into many types according to different parameters by means of the following diagram [65].

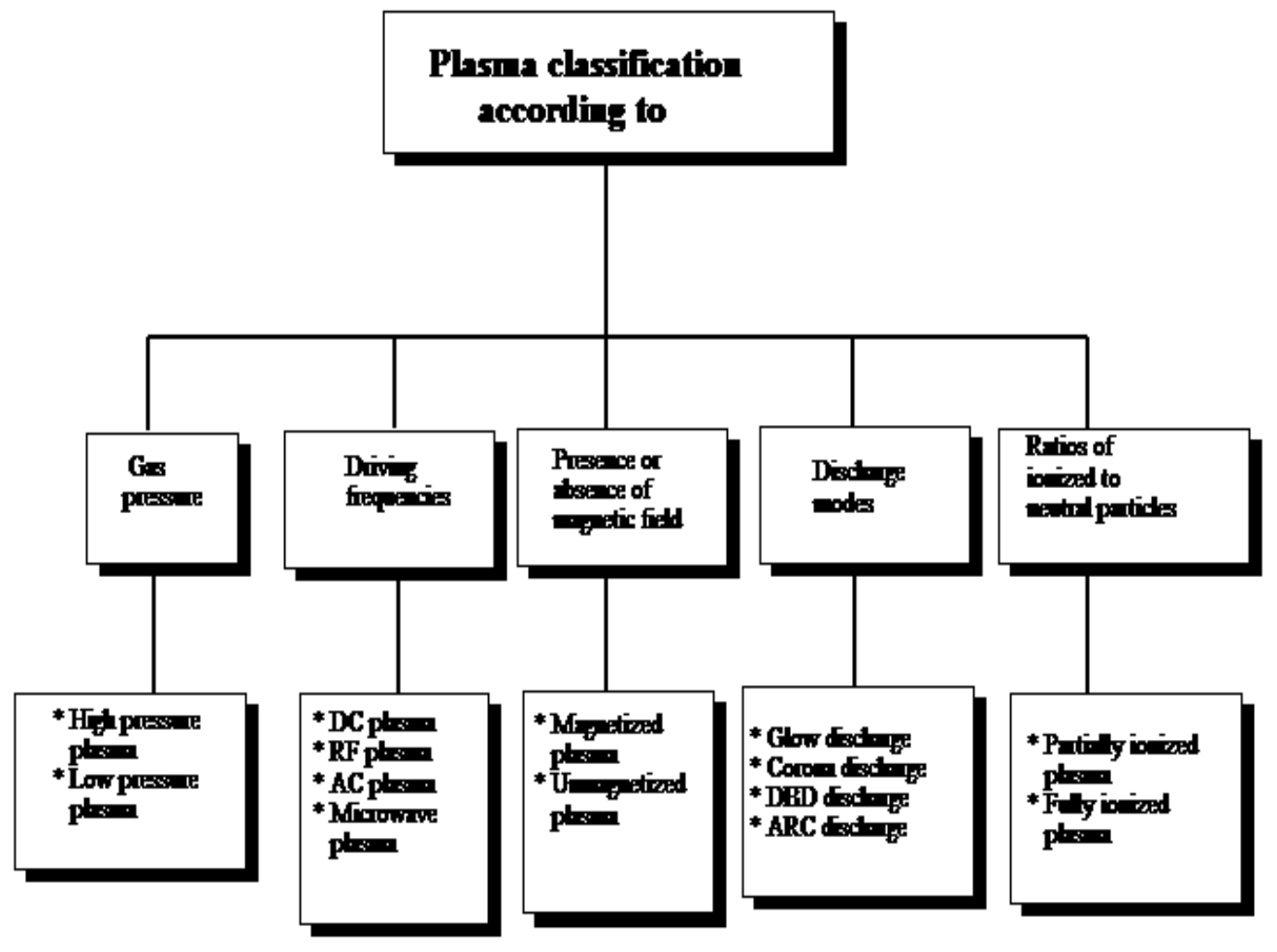


Plasma classification-according to gas pressures-into high or low pressure has gained much importance in the field of textile treatment. We will be dealing in the following section with the effect of the choice of the operating pressure on plasma use.

\section{Operating Pressure}

Plasma generation may be performed at various pressures, including low (vacuum), high (atmospheric) pressure. The operating pressure of the working gas is a significant factor in choosing a plasma source because it restricts the choice of reactor technology and the type of source used forprocessing application. The most critical choice with respect to pressure is whether the process is to be operated under vacuum (low) or $1 \mathrm{~atm}$ (high). If a source is operated at $1 \mathrm{~atm}$, batch-processing and vacuum equipment are not required; while, under vacuum both are required, and their cost is relatively expensive to the vacuum pressure [66].

\section{Low Pressure Plasma (Vacuum)}

Low pressure plasma has found wide applications in materials processing and play a key role in manufacturing semiconductor devices [67-70]. They generate high concentrate - ions of reactive species that can etch and deposit thin films at rates up to $10 \mu \mathrm{m} / \mathrm{min}$. Low pressure plasma is proven methods for surface modification. Vacuum devices provide a microscopically through, chemically mild, and mechanically nondestructive means for the removal of adsorbents such as dust, grease, and fatty acids or bacteria [69]. The ions produced in the plasma can be accelerated toward a substrate to cause directional etching of submicron features. Operating the plasma at reduced pressure has several drawbacks. Vacuum systems are expensive and require maintenance. Load locks and robotie assemblies must be used to shuttle materials in and out of vacuum. Also, the size of the object that can be treated is limited by the size of the vacuum chamber [70]. Low pressure plasma may be generated using a DC power supply thus providing a glow discharge, or a RF power supply producing a quasi-glow discharge or more specifically a quasi-neutral plasma bulk formed between two sheaths [69].

\section{- DC Glow Discharge}

A glow discharge is the oldest type of plasma; it is produced at reduced pressure and assures the highest possible uniformly and flexibility of any plasma treatment [71]. It is defined as a partially ionized gas containing equal volume concentrations of positively and negatively charged species with different concentrations of ground-state and excited species. This partially ionized gas may be generated by subjecting the gas to very high temperature, or to a strong electric field, or excited by a radioactive source or strong photoemission [69]. The electric field is induced by a direct current. Direct current (DC) discharge is comprised of a self-consistent combination of a cathode surface, cathode dark space, negative glow region, faraday dark region, and a positive column. Most of the applied voltage appears across the space between the cathode and the negative glow [69].

\section{High Pressure Plasma (Atmospheric)}

Although most previous research has focused on vacuum systems, their high cost and production limitations have led to the development of higherpressure (atmospheric) devices. To create a more economical, continuous, or high-speed process, a working pressure at or near $1 \mathrm{~atm}$ is a necessity. Atmospheric pressure plasmas overcomes the drawbacks of vacuum operation and offer industry open perimeter, on-line, continuous, large area processing, unlike closed perimeter vacuum systems [72]. Atmospheric-pressure plasma is used in a variety of materials processes. Traditional sources include transferred arcs, plasma torches, corona discharges, dielectric barrier discharges, and plasma jet. In arcs and torches, the electron and neutral temperatures exceed $3000{ }^{\circ} \mathrm{C}$ [70]. While in corona and dielectric barrier discharges produce non-equilibrium plasmas with gas temperatures between $50-400{ }^{\circ} \mathrm{C}$. Recently, an atmosphericpressure plasma jet has been developed, which exhibits many characteristics of a conventional, low-pressure glow discharge. In the jet, the gas temperature ranges from $25-200{ }^{\circ} \mathrm{C}$ [70].

\section{- Plasma Torch}

A clod plasma torch was first described by Koinuma et al. [73]. The powered electrode consists of a metal needle with a thickness of $1 \mathrm{~mm}$. This needle is inserted into a grounded metal cylinder. In addition, a quartz tube is placed between the cathode and anode, which makes this device resemble a dielectric barrier discharge [70]. Koinuma and coworkers [74] measured the electron temperature in the plasma effluent with a Langmuir probe and found it to be between 1-2 $\mathrm{eV}$ depending on the gas composition.

- Corona Discharge

A corona discharge appears as a luminous glow localized in space around a point tip in J. Text. Color. Polym. Sci. 16, No. 1 (2019) 
a highly no uniform electric field. The corona may be considered a Thownsend discharge or a negative glow discharge depending upon the field and potential distribution [75]. The apparatus consists of a metal tip, with a radius of about 3 $\mu \mathrm{m}$, and a planar electrode separated from the tip by a distance of 4-16 $\mathrm{mm}$ [76]. The plasma usually exists in a region of the gas extending about $0.5 \mathrm{~mm}$ out from the metal point. In the drift region outside this volume, charged species diffuse toward the planar electrode and are collected [70].

\section{- Plasma Jet}

This new source consists of two concentric electrodes through which a mixture of helium, oxygen, and other gases flow. By applying 13.56 $\mathrm{MHz}$ RF power to the inner electrode at voltage between $100-250 \mathrm{~V}$, the gas discharge is ignited $[70,77-78]$. The ionized gas from the plasma jet exits through a nozzle, where it is directed onto a substrate a few millimeters downstream [70]. Under typical operating conditions, the gas velocity is about $12 \mathrm{~m} / \mathrm{s}$ with the effluent temperature near $150{ }^{\circ} \mathrm{C}$ so far. This source has been used to etch polyamide, tungsten, tantalum, and silicon dioxide [77], as well as to deposit silicon dioxide films by plasma-assisted chemical vapor deposition (CVD) [78].

\section{- Dielectric Barrier Discharge (DBD)}

Dielectric barrier discharges are also called "silent discharge" and "atmospheric-pressureglow discharge". DBD are low temperature pulsed discharges usually working at atmospheric pressure [79, 80]. It consists of two metal electrodes separated by a gap of some millimeters and excited by a low frequency voltage [81]. The name DBD derives from the fact that at least one of the electrodes of the AC-powered discharge gap is covered by a dielectric material [82]. Characteristics for DBDs include the presence of insulating coating layers which covered one or both electrodes or on dielectric structures in the discharge gap. This coating prevents RF arcs and allows the surface charge build up that carriers the discharge form on half of the RF cycle to the next [66]. Because of the presence of the dielectric barriers, these electrode configurations cannot be operated with DC-fields. Typically, they are operated with sinusoidal wave currents, square wave currents or pulsed wave forms between the line frequency and RF frequencies [83]. DBDs are normally operated in one of the parallel plate or cylindrical configurations. The parallel plate configuration is used to surface treat fast moving webs and films, and the annular volume of the cylindrical configuration is used to treat air flow for ozone production [66].

DBDs used industrially usually operate at 1 atm with air as the working gas. An exception occurs when air is enriched with oxygen to increase the efficiency of ozone production. Some commercial operated at line frequency (50 or $60 \mathrm{~Hz}$ ) but optimum ozone production appears to occur at RF frequency on the order of 10 KHz. DBDs characteristically operate at applied voltages of several tens of kilovolts rms and at electric field comparable to the breakdown electric field of the working gas, $30 \mathrm{kV} / \mathrm{cm}$ for air. An individual filamentary discharge is initiated when a high voltage is applied between the electrodes such that the electric field in the open gap equals or exceeds the breakdown strength of the ambient gas. Electron emission from the surface of the dielectric coating on the instantaneous cathode is stimulated by UV photo-emission or ion induced secondary electron-emission. These electrons are accelerated in the electric field to energies that equal or exceed the ionization energy of the gas, and create an avalanche in which the number of electrons doubles with each generation of ionizing collision [66]. The high mobility of the electrons compared to the ions allows the electron swarm to move across the gap in directions measured in nanoseconds. The electrons leave behind the slower ions, and various excited and active species that may undergo further chemical reactions. When the electron swarm reaches the opposite electrode, the electrons spread out over the insulating surface, counteracting the positive charge on the instantaneous anode. This factor combined with the cloud of slower ions left behind reduces the electric field in the vicinity of the filament and terminates any father ionization along the original track in time scales of tens nanoseconds. The filaments produced by each avalanche characteristically are a few tens to a few hundred nanometers in diameters and their roots where they contact the dielectric surface can cause pitting or pin-holing of a work-piece [66].

\section{Comparison of Plasma Sources}

Low-pressure plasma discharges are widely used in materials processing, because they have a number of distinct advantages:

- Low breakdown voltage;

- A stable operating window between spark ignition and arcing; 
- An electron temperature capable of dissociating molecules (1-5eV), but a low neutral temperature,

- Relatively high concentrations of ions and radicals to drive etching and deposition reactions;

- A uniform glow over a large gas volume.

It is instructive to compare atmosphericpressure plasmas against these criteria, to see if any of these sources can match the performance of low-pressure discharges [70]. Shown in Table I are breakdown voltages for the different plasma sources. The plasma jet has a $\mathrm{V}_{\mathrm{b}}$ below that of a low pressure discharge, whereas the other atmospheric pressure plasmas have breakdown voltage above $10 \mathrm{kV}$. A comparison of the I-V curves reveals that the corona and the plasma jet exhibit normal and abnormal glow regions that are characteristic of weakly ionized plasma. However, the current in a corona is limited to below $10^{-4} \AA$, which is insufficient to ionize a reasonable volume of the gas [70]. However, in the corona and the dielectric barrier discharge, the plasma is restricted to a small region of space and is not available for uniformly treating large substrate areas [84].

Presented in Table II are the densities of charged species in the different plasma discharges. Except for the transferred arc and plasma torch, all the plasmas exhibit electron densities in the same range as a low-pressure discharge [70].

\section{Plasma Substrate Interaction}

In the plasma bulk, reactive species (positive and negative ions,atoms, neutrals, metastables and free radicals) are generated by ionization, fragmentation, and excitation. These species lead to physical and chemical interactions between plasma and the substrate surface depending on plasma conditions such as gas, power, pressure, frequency, and exposure time. The depth of interaction and modification, however, is independent of gas type and is limited to $5 \mathrm{~mm}$ [85].

\section{Physical Phenomena in Plasma Assisted Surface Modifications}

- Etching / Re-Deposition

Plasma etching is the key process for the removal of surface material from a given substrate.

TABLE I. Breakdown voltages of the plasma discharges.

\begin{tabular}{|c|c|}
\hline source & $\mathbf{V}_{\mathbf{b}}(\mathbf{K v})$ \\
\hline Low-pressure discharge & $0.2-0.8$ \\
\hline Arc and plasma torch & $10-50$ \\
\hline Corona & $10-50$ \\
\hline Dielectric barrier discharge & $2-25$ \\
\hline Plasma jet & $0.05-0.2$ \\
\hline
\end{tabular}

TABLE II. Densities of charge species in the plasma discharges.

\begin{tabular}{|c|c|}
\hline source & Plasma density $\left(\mathbf{c m}^{-3}\right)$ \\
\hline Low-pressure discharge & $10^{8}-10^{13}$ \\
\hline Arc and plasma torch & $10^{16}-10^{19}$ \\
\hline Corona & $10^{9}-10^{13}$ \\
\hline Dielectric barrier discharge & $10^{12}-10^{15}$ \\
\hline Plasma jet & $10^{11}-10^{12}$ \\
\hline
\end{tabular}


This process relies on the chemical combination of the solid surface being etched and the active gaseous species produced in the discharge. The resulting etched material will have a lower molecular weight and the topmost layer will be stripped. In previous methods, such as chemical wet processing, plasma has shown much more controllability and a much finer resolution [86]. Etching can proceed by physical sputtering or chemical reaction and ion-assisted mechanisms. Although four distinctive processes are described, often, parallel or serial combinations are employed for specific substrate modification [69]. The first process, sputtering, is a purely physical and unselective process. Energetic ions crossing the sheath transfer large amounts of energy to the substrate, resulting in the ejection of surface material. This mechanical process is sensitive only to the magnitude of bonding forces and structure of the surface, rather than its chemical nature [87]. Since sputtering requires high amounts of energy, the rates are generally low and the yield is typically on the order of one atom per incident ion [88]. Unlike sputtering, chemical etching is a highly selective process due to its inherent sensitivity to the differences in bond type and chemical consistency process involves gasphase etchant atoms or molecules formed through collisions between energetic free electrons and gas molecules, which stimulate dissociation and reaction of the feed gas. These etchants chemically react with the surface to form volatile products [87]. This process is invariably isotropic or non-directional, since the gas-phase etchants arrive at the substrate with near uniform angular distribution. The etch rate for pure chemical etching can be quite large due to a high flux of etchants to the substrate [88]. The third technique, reactive ion etching, is characterized by a combination of physical sputtering and chemical activity of reactive species. In most situations, the chemistry in this process is provided by the neutral species. Basic reactive ions etch system proceed by:

- generating active species in the plasma

- transporting reactive intermediates from the plasma bulk to the substrate surface

- absorbing reactive radicals and "active site" formation

- concluding with chemical reaction and desorbing volatile reaction products [89]. Due to this combined process, a greater amount of etched products will be produced than with sputtering or chemical etching alone. Both chemically selective and an isotropic etching will occur, and their ratio can be controlled. With a similar method, ion-enhanced inhibitor etching can also be an effective method for surface removal. This system shares most features of reactive ion etching, but with the inclusion of inhibitor precursor molecules that absorb or deposit on the substrate. The polymer-forming inhibitor species may originate from the feed gas, additives, sputtered reactor material, or a resist mask. During this process, the plasma chemistry initiates the formation of a thin film on the sidewalls of the etched feature, which prevents chemical attacks [90]. In addition to the etching methods described above, it should also be noted that volatile and non-volatile etched material may return to the substrate surface, further affecting the overall surface modification. This is known as re-deposition and backscattering, which depends on the volatility of the etched material.

\section{-Surface Morphology and Roughness Changes \\ Due to the etching mechanism on polymer} surface, morphological and topographical changes will occur. These changes are visible through atomic force microscopy (AFM) or scanning electron microscopy (SEM). Since most polymers are semi-crystalline, that is, they contain both crystalline and amorphous regions; they produce very distinctive morphology changes due to selective etching [69]. Padhye et al.[91] observed that both PET and nylon 6,6 filaments showed selective etching patterns when exposed to nitrogen plasma. For the PET treated samples, they reported "seashore" like structure, will an average separation of $600 \AA$ between adjacent elongated units. These long periods are consistent with amorphous regions within the polymer. Due to the loosely bound structure of the amorphous regions, it is concluded that these are much more susceptible to etching. Similar results were observed for the nylon 6,6 samples, but due to their spherulitie crystal structure of PET, the etch pattern varied. It consisted of fibrillar branches expanding from the fiber centre. Identical results were obtained for both PET and nylon when comparing weight loss from plasma exposure to the degree of crystallinity, they showed that the weight loss decreased with increasing percent crystallinity [92]. 


\section{- Chain-Scission}

Chain- scission is defined as any event that results in the breakage of one polymer molecule into two or more parts. This can occur through a direct rearrangement of the backbone into two separate entities. Or by the loss of side groups and consequent rearrangement, which inherently results in molecular division [93]. Both processes can occur as a result of etching via plasma exposure. The first interaction involves ion bombardment, in which ion energy is transferred to the polymer molecules comprising the substrate. Bond scission and radical formation then occur, causing weight loss and a reduction in molecular weight [94].

Chemical Phenomena in Plasma-Assisted Surface Modifications

\section{- Radical Formation}

In addition to physical modifications, plasma exposure leads to changes in the elemental composition of the polymer surface. This includes the formation of free radicals. Electron spin resonance (ESR) signals of polymeric materials exposed to plasma, show new radical formations even in short durations. These sites include not just terminating radicals but mid-chain and stable monomer-derived radicals. ESR also has indicated dangling-bond sites, which are suitable to industry of polymers [95]. The formation of radical sites occurs through ionization or excitation of the polymers through electrostatic interaction between fast moving electrons and the orbital electrons in the polymers. The consequent ionization leads to molecular fragmentation and the formation of a free radical. Similarly, excitation leads to dissociation of the excited polymers, also forming free radicals.

$\mathrm{e}^{-}+\mathrm{AB} \rightarrow \mathrm{AB}^{+}+\mathrm{e}^{-}$(Ionization)

$\mathrm{e}^{-}+\mathrm{AB} \rightarrow \mathrm{A}^{+}+\mathrm{B}+\mathrm{e}^{-}$

$$
\mathrm{AB} \rightarrow \mathrm{AB} \quad \text { (Excitation) }
$$

$\mathrm{AB} \rightarrow \mathrm{A} \cdot+\mathrm{B} \cdot($ Dissociation $)$

If the free radicals formed are unstable, they will rapidly undergo recombination. Stable radicals, however, will remain in the polymer as living radicals. These radical sites can then "catalyze" the next steps for further chemical processing such as initiation of grafting, crosslinking, or functional group attachment [94].

\section{- Grafting}

Plasma grafting, often referred to as plasma graft-copolymerization, can occur through either of the following two mechanisms [96]: The creation of active species on the polymer surface, followed by contact with monomer In this mechanism, free radicals are formed on the polymer surface as a result of inert gas plasma treatment. These radicals can either directly initiate grafting or be converted into peroxide or hydro peroxides by the inclusion of an oxidative gas. These activated peroxides will also initiate grafting in the presence of the monomer species [97]. Direct grafting of the polymer with common or unconventional monomers under "monomer" plasma conditions: Unlike the previous method, this involves a combined plasma and monomer exposure in one step by the use of gaseous monomers in the working gas mixture [96]. Both techniques have shown great advantages over conventional grafting by offering a large range of chemical compounds to be used as monomers, varying thickness of monomer layers, and limited destruction.

\section{- Polymerization}

Plasma-induced polymerization can be defined as a film-forming process by which thin films are deposited directly onto the surface of a given substrate without any fabrication. The elemental reactions occurring during this process include fragmentation of the monomer molecules, the formation of reactive sites (radicals), and recombination of the activated fragments. This mechanism follows similar steps to that of traditional radical polymerization with the inclusion of a possible re-initiation step [94]:

Step 1: Initiation-Radicals are formed in the gas phase and at the substrate which initiate polymerization.

$\mathrm{M}_{(\mathrm{g})}+\mathrm{e} \rightarrow 2 \mathrm{R}_{(\mathrm{g})}+\mathrm{e}$

$\mathrm{S}-\mathrm{X}+\mathrm{e} \rightarrow \mathrm{S}-\mathrm{Rn} .+\mathrm{H}$.

Step 2: Propagation - Continual growth of the polymer chain through the successive addition of monomer molecules and the shifting of the active centre.

$\mathrm{R}_{\mathrm{n}}+\mathrm{M}_{(\mathrm{g})} \rightarrow 2 \mathrm{R}_{\mathrm{n}+1}$
$\mathrm{~S}-\mathrm{R}_{\mathrm{n}}+\mathrm{M}_{(\mathrm{g})} \rightarrow \mathrm{S}-\mathrm{R}_{\mathrm{n}+1}$

Step 3: Termination - The terminal radical on a growing chain is destroyed or rendered inactive through bonding with another chain.

$\mathrm{R}_{\mathrm{n}}+\mathrm{R}_{\mathrm{m}} \rightarrow \mathrm{X}_{\mathrm{n}+\mathrm{m}}$

J. Text. Color. Polym. Sci. 16, No. 1 (2019) 
$\mathrm{S}-\mathrm{R}_{\mathrm{n}}+\mathrm{R}_{\mathrm{m}} \rightarrow \mathrm{S}-\mathrm{X}_{\mathrm{n}+\mathrm{m}}$

$\mathrm{S}-\mathrm{R}_{\mathrm{n}} \cdot+\mathrm{S}-\mathrm{R}_{\mathrm{m}} \rightarrow \mathrm{S}-\mathrm{X}_{\mathrm{n}+\mathrm{m}}+\mathrm{S}$

Step 4: Reinitiating - Radical formation in the deposited polymers by activation of electrons, ions, and radicals.

$\mathrm{X}_{\mathrm{n}}+\mathrm{e} \rightarrow \mathrm{R}_{\mathrm{n}}+\mathrm{H}+\mathrm{e}$

$\mathrm{X}_{\mathrm{n}+\mathrm{m}}+\mathrm{e} \rightarrow \mathrm{R}_{\mathrm{n}}+\mathrm{R}_{\mathrm{m}} \cdot+\mathrm{e}$

$\mathrm{S}-\mathrm{X}_{\mathrm{n}}+\mathrm{e} \rightarrow \mathrm{S}-\mathrm{R}_{\mathrm{n}}+\mathrm{H}+\mathrm{e}$

where $\mathrm{M}_{(\mathrm{g})}$ = gaseous monomer, $\mathrm{R}$ - = radical, $\mathrm{S}=$ surface site, $\mathrm{X}=$ monomer or polymer segment.

\section{- Cross-linking}

Cross- linking occurs when two polymer molecules join to form one large molecule / network. Cross-linking can result in improved mechanical properties, decreased solubility, elimination of the melting point, and increased resistance to corrosive attack, all of which are desirable[93]. During plasma exposure of polymeric materials, both chain-scission and cross-linking occur randomly and simultaneously. The predominance of one process over the other will depend on the polymer structure and crystallinity, temperature, and gas composition. If scission/ etching are the dominating process, then degradation of the physical properties will occur, and the polymer may become unstable. For this reason, an exact balance must be obtained to control the competing processes [93].

Ways of Looking at Plasma Technology for Textiles

The potential of plasma-for-textiles can be looked upon from more different engineering, textile, financial and environmental aspects than any other textile related technology. Everything depends on what a textile wants to accomplish with the acquisition of a plasma reactor system. It is therefore essential for the textile to get acquainted with all these aspects before decisions on the application of plasma in their company can be made. The list below does not pretend to be complete [71].

\section{Plasma Treatment as a Step in the Total Textile Production Cycle}

- A plasma treatment could replace an existing wet processing step. Examples are treatments for in wetting and adhesion properties, such as advantageous for dyeing, coating and making composite saving environment-related costs is a priority.

J. Text. Color. Polym. Sci. 16, No. 1 (2019)
- The plasma treatment can be final step in creating a textile with novel properties. Here textiles produced with properties that cannot be induced via wet processing. Added value is a priority.

Plasma Treatment as a Means to Save Water, Materials and Energy

This environmental aspect is without doubt the most exposed advantage of plasma technology. Its importance was due to ever increasing environment-related costs. However, its relevance depends on above mentioned cases. The largest advantage will be experienced when a plasma treatment can replace a wet process completely. Even though such cases are not common, and in view of a continuing cost increase water extraction and discharge, plasma technology becomes relatively more cost effective every day. Affiliated cost savers are:

- Reduction of the amount of chemicals needed in wet treatment following the plasma treatment; exhaustion of chemicals from the bath; reduced BOD/COD of discharged processing water.

- Shortening of the wet processing time; this compensates for the possible extra time required for the treatment.

- Reduction of the needed wet processing temperature; saving heating energy. This adds to the efficient energy during the plasma treatment.

Extra advantages can be that the finished textile shows better performance and improved fastness property has an extra added value.

\section{Plasma Treatment as a Means to Create Unique} Textile Properties

Though currently not very relevant in produced amounts (square meters), this type of high-performance text certainly grow in economic importance. Due to their high added value even small textile batches can produce high profit, though perfect process control is absolutely necessary. Typically, textiles for medical applications in the sector of biotechnology are expected to increase in importance. Applications are special selective filth biocompatibility, growing of biological tissues, etc.

\section{Continuous (i.e. atmospheric) Versus Batch}

(i.e. vacuum) Plasma Processing

Most of the current atmospheric plasma reactor development is done because-supposedly-the textile 
induces only use a plasma reactor when it can be integrated in a continuous production/finishing line. Extra requite are ability of full width textile treatment (at least $2 \mathrm{~m} /$ wide) and high processing speed (at least $20 \mathrm{~m} / \mathrm{min}$ ) this reason, vacuum technology is regarded as being noncompetitive. A thorough review of literature shows that currently available industrial vacuum reactors treat a $2000 \mathrm{~m}$ fabric roll in all-including batches of 1 hour duration. On the other hand, some publications that are stressing the continuous aspect of atmospheric treatments are produced to announce a processing speed i.e. treating $2000 \mathrm{~m}$ of fabric would take more than 16 hours! This extreme difference processing speed from general, but the example makes clear that a complete and objective comparison is desirable in order to the right conclusions regarding which technology to choose.

More, it must be stressed that- in comparison with atmospheric discharges-plasmas created at low pressure superior in application flexibility, treatment homogeneity and stability of treatment results. This is due inherent difference between physics at reduced pressure and physics at atmospheric pressure. These differences will not become smaller in the future. Research groups are continuously finding solutions that the limits of atmospheric reactors, but it can be expected that this will come with increased hardware complex costs. On the side of up scaling, an advantage of vacuum reactors is their ability to incorporate a long (e.g. $20 \mathrm{~m}$ ) treatment zone in a compact manner, similar to textile dryers or steamers. Similar solutions have not been atmospheric reactors due to the vertical space needed for the electrode and discharge control system. Why treatment durations should prove necessary, an unpractical long reactor or slow processing speed are current options.

\section{References}

1- P.H. Greaves, B.P. Saville, "Microscopy of Textile Fibers", 1st Edition, Bios Scientific, London, P.1 (1995).

2- I. Emery, "The Primary Structure of Fabrics", 1st Edition, Waston-Guptill Publications, Washing ton, P.4 (1995).

3- F. Sadov, M. Korchagin and A. Matetsky, "Chemical Technology of Fibrous Material", Mir, Moscow, P.11 (1973).

4- G. EL-Nouby, H.A. Azzam, "Spinning Technology”, 1stEdition, Industrial Education College Textile Technology Dept., P.2(2003).
5- P.R. Lord, "Hand Book of Yarn Production Technology Science and Technology", 1st Edition, Wood Head Publishing Ltd, Cambridge, England, P.7-8 (2003).

6- I.V. Degruy, J.H. Carra and W.R. Goynes, "The Fine Structure of Cotton”, Vol.6, Marcel Dekker, Inc., New York, P. 90 (1973).

7- S.J. Kadolph, A.L. Langford, "TEXTILES", 8th Edition, Prentice-Hall, Inc., P. 130-150 (1998).

8- A. Hebeish, A. Kantoush and M.H. EL-Refie, J. Applied Polymer Science, 15, 1921(1971).

9- O.J. Mc Millen, K.M. Decosas, A.S. Cooper, J.R., C. Hamalainin, A.L. Murphery and E.E. Pollard, American Dyestuff Reporter, 49, 839 (1960).

10- D.K.R. Chaudhari, Polymer Science, 51, 373 (1961).

11- A. Hebeish, P.C. Metha, J. Applied Polymer Science, 12, 1625 (1968).

12- H. Rinehart, "Essentials of Textiles", 4th Edition, Winston, Inc., Orlando, Florida, P.66-68, 105-107 (1988).

13- F. Happey, "Applied Fiber Science", Vol.3, Academic Press, San Francisco, P. 18 (1979).

14- B.P. Corbman, "Textiles: Fiber to Fabric", 6th Edition, Mc. Graw-Hill Book Company, New York, P. 73 (1983).

15- E.R. Trotman, "Dyeing and Chemical Technology of Textile Fiber", 6th Edition, Edward Arnold Publication, London, P.28 (1990).

16- R.T. O, Connor, "Instrumental Analysis of Cotton Cellulose and Modified Cotton Cellulose", Vol.3, Marcel Dekker, Inc., New York, P.160 (1972).

17- M. Harris, "Hand Book of Textile Fibers", 1st Edition, Textile Book Publishers, Inc., New York, P. 67 (1954).

18- S. Marshall, A. Todd, Trans.Faraday Soc., 49, 77 (1953).

19- V.A. Shenai, "Technology of Textile Processing”, Vol. 1, Sevak Publications 306, Shri Hanuman Industrial, Mumbai, P.5-9 (2000).

20- M.L. Joseph, "Essentials of Textiles", 2nd Edition, Holt, Rinehert and Winston, New York, P.178-180 (1980).

21- P.G. Tortora, B.J. Collier, "Understanding Textiles", 5th Edition, Prentice Hall, Inc., New York, P.95-97 (1997).

J. Text. Color. Polym. Sci. 16, No. 1 (2019) 
22- J. Gordoncook, "Hand Book of Textiles Fibers", 4th Edition, Merrow Publishing Co., England, P. 354 (1968).

23- I.B. Wingate, "Textile Fabrics and Their Selection", 7th Ed., Prentice-Hall,Inc., Engle Wood Cliffs, P.350 (1976).

24- E. R. Trotman, "Dyeing and Chemical Technology of Textile Fibers", 3th Ed., P.90, London (1963).

25- D.M. Nunn, W. Beckmann, D. Blackburn land and R. Broadhurst, "The Dyeing of Synthetic Polyester and Acetate Fiber", 1th Edition, Dyer Co. Publications Trust, P. 136 (1979).

26- L.W.C. Miles, Society of Dyers and Colorists, 4 , 188 (1990).

27- J.Shore, "Colorants and Auxiliaries, Organic Chemistry and Application Properties", Society of Dyers and Colorists, Brad Ford, Vol.1, (1990).

28- I. Holme, "Coloration of Technical Textiles", In Hand Book of Technical Textiles, Ed.A.R. Horrocks and S.C. Anand, Woodhead, Cambridge, P. 187(2000).

29- J.Shore, "Cellulosics Dyeing", Society of Dyers and Colorists, Brad Ford, P. 122 (1995).

30- E.A. Wich, Am.Ink Maker,Oct.(1974).

31- R. Eisenlohr, V. Giesen, International Dyer, 180, 12 (1995)

32- F.R. Alsbery, H.G. Conner, W.F.Liquorice and S.W.Milne, International Dyer and Textile Printer, $141,151,(1969)$.

33- K. Kinnersly, "Dyeing and Screen-Printing on Textiles", A and C Black Publishers, London, P.52 (2003).

34- H. Barth, Bayer Farben Revue,15, 64 (1969).

35- H.Barth, Bayer Farben Revue, 53, 16 (1969).

36- R.L. Whistler, J.N. Bemillr, "Industrial Gums, Polysaccharides and Their Derivaties", 3th Ed., Academic Press,Inc.,P. (1993).

37- R.H. Mc Dowell, "Properties of Alginates", 2nd Ed., Alginate Industries 1 td, P.45 (1961).

38- M.D. Teli, U.V.Vyas, Colourage, 37, 15 (1990).

39- W.Romp,G.L.Axon and T.Thompson, American Dyestuff Reporter, 72, 2 (1983).

40- M.M. El-Molla, "Some Novel Methods For Isolation, Characterization and Ultilization of Sodium Alginate From Egyption Algae", M.Sc. Thesis, Faculty of Science, Cairo Unv., P.45 (1997).

J. Text. Color. Polym. Sci. 16, No. 1 (2019)
41- T.Hdst, Textile Chemistry Col., 11, 53 (1979).

42- J.T. Marsh, "Textile Science", 4th Ed., Chapman And Hall Ldt., London, P.253 (1958).

43- D.Blackburn, "Textile Processing”, Dep.of Edu., Columbia, South Caroline, Vol.2, P.234 (2000).

44- V.A. Shenai, "Chemistry of Organic Textile Chemicals", 2nd Ed., Sevak Publications, Bombai, P. 127 (1995).

45- T.L. Vigo, "Textile Processing and Properties", Elsevier, London, Vol.11, P.174 (1994).

46- T.L. Vigo, "Textile Processing and Properties", Elsevier, London, Vol.12, P.177-185 (1994).

47- J.S. Schofield, "Review Progress Coloration”, 14, 69 (1989)

48- L.N. Miles, “Textile Printing”, 2nd Ed., Society of Dyers and Colorists, P. 1,53 (1994).

49- A.A. El-Halwagy, A. Ragheb and M.A. ElKashouty, Sci. Int (Lohore), 3, 139 (1991).

50- B. Balakrishnaiah, R. Ashal, Text. Dyer and Printing, 27, 19 (1994).

51- A. Bohringer, International Textile Balletin, 41, 46 (1995).

52- R. Ross, "Foams', Encyclopedia of Science and Technology, Mc Graw-Hill, New York, Vol. 5, P.402 (1977).

53- L.W. Miles, "Textile Printing", 2nd Ed., Society of Dyers and Colorists, P. 240-272 (1994).

54- E.A. Ghoneim, "Some Studies on Foam Printing", M.Sc. Thesis, Faculty of Applied Arts, Helwan Unvi., P.50-53 (2000).

55- Z. Johannes, American Dyestuff Reporter, 71, 46 (1982).

56- B.N. Bandyo Padhay, Text. Dyer and Printer, 13, 35 (1980).

57- A. Bohringer, International Dyer 184, 17 (1999).

58- C.E. Vellins, "Transfer Printing", The Chemistry of Synthetic Dyes, VIII, Academic Press, New York, P.191-220 (1978).

59- H.U. Poll, U. Schladitz and S.Schreiter, Surf. Coat. Technol., 142, 489 (2001).

60- A. M. Bakry, "Investigations of Dc Discharge", Ph.D. Thesis, Faculty of Science, Al-Azhar Univ., P.1-10 (2005). 
61- F. F. Chen, "Introduction to Plasma Physics and Controlled Fusion", 2nd Ed., Plenum Press, New York, Vol.1, (1990).

62- L. F. Jones, "Ionization and Breakdown in Gases", Methuen Co., London, P. 344-350 (1956).

63- A. A. Garamoon, Fourth Work Shop of Plasma and Laser Physics, Cairo, Egypt, Feb., P. 26-29 (1996).

64- E. Nasser, "Fundamentals of Gaseous Ionization and Plasma Electronics", Wiley. Interscience, New York, P.110-120 (1971).

65- M. A. Lieberman, A. J. Lichtenbery, „Principals of Plasma Discharge and Materials Processing“, John Wiley And Sons, Inc., P. 64-75 (1994).

66- J. R. Roth, "Industrial Plasma Engineering”, Published by Institute of Physics, London, Vol.2, P.40 (2001).

67- R. W. Smith, D. Wei, and D. Apelian, Plasma Chem. Plasma Process, 9, 1, 135 (1989).

68- P. Fauchais, A. Vardelle, "Thermal Plasma", IEEE Trans. Plasma Sci., 25, 1258 (1997).

69- C. W. Kand, C. W. M. Yuen, RJTA, 10, 49 (2006).

70- A. Schütze , J .Y. Jeeng, S.E. Babayem , J. Park , G.S.selwyn and R.F. Hicks, IEEE Transactions on plasma Sci ., 26, 6 (1998).

71- J. Verschuren, P. Kiekens, www. kotonline.com / English_pages_basliklar / kieken.asp

72- P. A. F. Herbert, E. Bourdin, J. of Coat. Fabrics, 28, (1999).

73- H. Koinuma, H. Ohkubo, T. Hashimoto, K.Inomata,T. Shiraishi, A. Miyanaga and S. Hayashi, Appli. Phys. Lett., 60, 816 (1992).

74- K. Inomata, N. Aoki and H. Koinuma, Jpn. J. Appl. Phys., 33, 197 (1994).

75- R. S. Sigmond, M.Goldman, "Corona Discharge Physics and Applications", In Electrical Breakdown and Discharge in Gases, E.E.Kunhardt and L.H.Luessen, Eds. New York: Plenum, P. 1-64 (1983).

76- M. Goldman, N. Goldman, "Corona Discharge in Gaseous Electronics", M.N.Hirsh and H.J. Oskam, Eds. New York Academic, Vol.1, P.219-290 (1978).

77- J.Y. Jeong, S.E.Babayan, V.J. Tu, J.Park, R.F.Hicks and G.S.Selwyn, Plasma Source Sci. Technol., 7, 282 (1998).

78- S.E. Babayan, J.Y. Jeong, V.J.Tu, J.Park, G.S. Selwyn and R. F. Hicks, Plasma Source Sci. Technol., 7, 286 (1998).

79- U. Kogelschatz, Hakone Vii, Greifswald, Allemagne, 6, 10 (2000).
80- B.elinsson,U.Kogelschatz, IEEE. Trans. Plasma Sci., 19, 309 (1991).

81- F.Massins,P.segur, Laboratoire de Genie Electrique,centere de physique des plasma et de leurs Applications University, (2002).

82- R.Bartnikas,M.R. Wertheimer, Appl. Phys., 38, 539 (2005).

83-S.paulusseu,R.Rego,o.Goossens1, D.Vangeneugden and k.Rose, Appl. phys., 38, 568 (2005) .

84- BLee, Y.kusano.N.Kato,K.Naito,T.Horiuchi and H.Koinuma, Jpn.J.Appl.Phys., 36, 2888 (1996).

85- W.Rakowsk,O.Wski,K.Bartosand J.zawadzki, "Plasma Treatment of Textiles - Potential Application and Future Prospects ", 8th Edition, Melli and Textilber: chte, p.301-303(1982).

86- B.N. Chapman, "Glow Discharge Processes: Sputting and Plasma Etching“, John Wiely and Sons, Inc., New Yourk, (1980).

87- D.M.Monos, D.L.Flamm , "Plasma Etching: An Introduction ", Academic Press, Inc., San Diego., (1989).

88- A.salama, A.Hashem, AYehia and A Gaber, Appl. Phys., 36, 252 (2003).

89- S.M.Rossnagel,J.J.Cuomo and W.D.West Wood, "Hand Book of Plasma Processing Technology ", Noyes publishing, New Yourk (1990).

90. R.J.Shul,S.J. peartan, "Hand Book of Advanced Plasma Processing Techniques" ,Springer-Verlag Berlin Heidelberg,German. (2000).

91- M.R. Padhy,N.V.Bhat and P.K.Mittal, Text. Res. J., 46, 502 (1976).

92- T.okuno,T .yasuda and H. yasuda, Text. Res. J., 62, 8,474 (1992).

93- R.L.Clough, S.W.shalaby, American Chemical Society, 63,60 (1996).

94-N. Inagaki, "Plasma Surface Modification and Plasma Polymerization", Tschnomic-Pup. Co., Inc., Lancaster, Pennsylvana, (1996).

95- M. Kuzuya, A. Noguchi, M. Ishikawa, A. Koide, K. Sawada,A. Ito and N. Noda, J. Physical Chemistry, 95, 6, 2398 (1991).

96- C.I. Smionescu, F. Denes, Cellulase Chemistry and TeChnology, 14, 285(1980).

97- J. Jagur-Groodzinski, "Heterogeneous Modifaction of Polymers : Matrix and Surface Reactions", Joh Wiley and Sons Ltd., Chichester, U K., (1997).

(Received $3 / 10 / 2018$; accepted 9/4 /2019)

J. Text. Color. Polym. Sci. 16, No. 1 (2019) 


\section{تطبيق البلازما في المنسوجات}

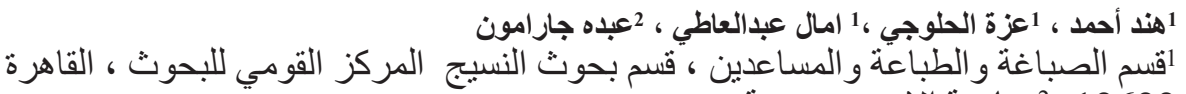

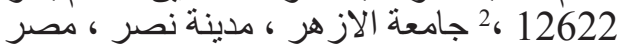

تم استخدام التعديل الكيميائي للأقشة السليلوزية في وقت مبكر كأداة لإضفاء خصائص جديدة عليها وزيادة

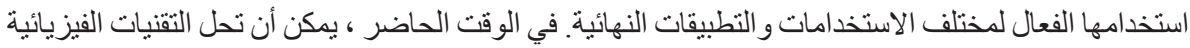

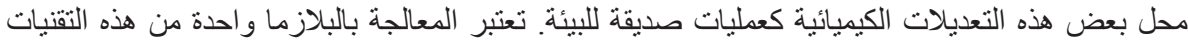

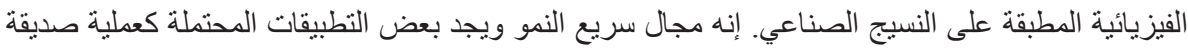

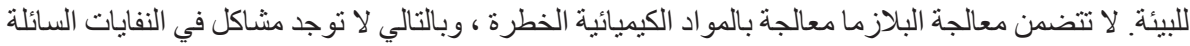
مقارنة بالمعالجة الكيميائية. 